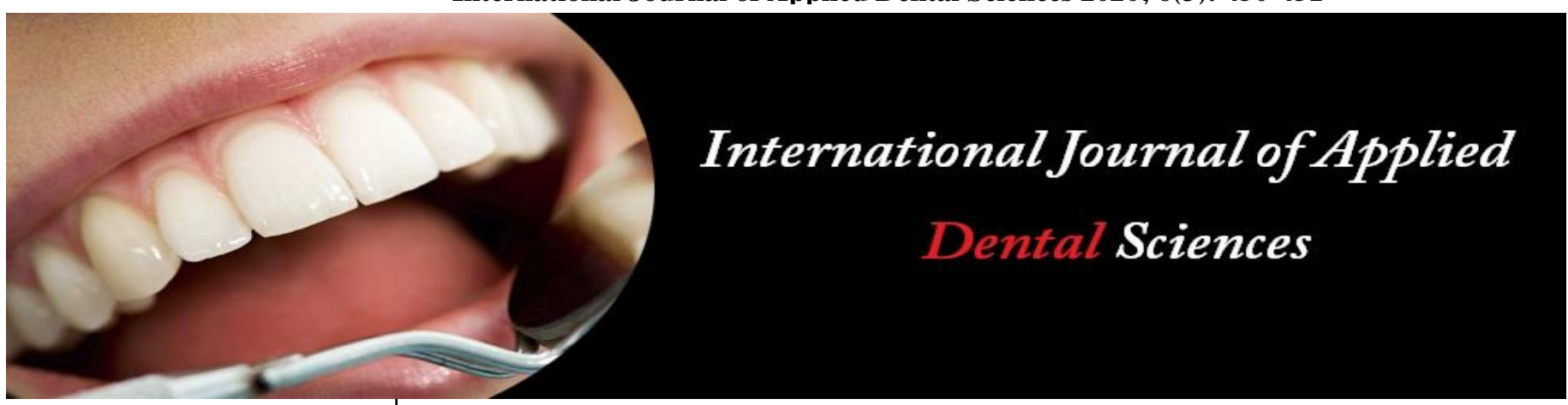

ISSN Print: 2394-7489

ISSN Online: 2394-7497

IJADS 2020; 6(3): 450-451

(C) 2020 IJADS

www.oraljournal.com

Received: 12-05-2020

Accepted: 14-06-2020

Shilpi Tiwari

Post Graduate Student,

Department of Conservative

Dentistry and Endodontics,

Vokkaligara Sangha Dental

College \& Hospital, Bangalore,

Karnataka, India

Meena Naganath

MDS Professor, Department of

Conservative Dentistry and

Endodontics, Vokkaligara

Sangha Dental College \&

Hospital, Bangalore, Karnataka India
Corresponding Author:

Shilpi Tiwari

Post Graduate Student,

Department of Conservative

Dentistry and Endodontics,

Vokkaligara Sangha Dental

College \& Hospital, Bangalore,

Karnataka, India

\section{Nonsurgical endodontic management of Mandibular first Premolar with 2 roots: A rare case report}

\section{Shilpi Tiwari and Meena Naganath}

DOI: https://doi.org/10.22271/oral.2020.v6.i3g.990

\section{Abstract}

The endodontic failure is usually due to the failure in recognizing the variations in root and its root canal anatomy. Hence, it is important to have a detailed knowledge of commonest possible aberrations and anamolies of the tooth being treated. Mandibular premolar is considered as "Endodontist Enigma" due its unpredictable root canal anatomy which often complicates the endodontic treatment. The present case report i.e mandibular first premolar with two roots highlights the importance of sound knowledge of root canal anatomy and the importance of dental operating microscope in treating such complex cases.

Keywords: Mandibular first premolar, bifurcated root, endodontic management

\section{Introduction}

A detailed sound knowledge of root canal anatomy and its variations is prerequisite for a successful endodontic outcome. Hence the anatomic variations like extra roots and canals should always kept in mind as missed canal can lead to a endodontic failure. "Slowey" has suggested mandibular premolar as "Endodontist Enigma" because of its unpredictable root canal anatomy ${ }^{[1]}$. The mandibular first premolar is usually single rooted $(97.1 \%)$, however literature revealed $2.7 \%$ incidence of two rooted and $0.2 \%$ incidence of three rooted mandibular first premolar. "Scott \& Turner" described the accessory root in mandibular premolar as "Tome's Root". Their anthropological review on ethnical differences indicates that aboriginal Australians and Sub Sahara African population showed highest incidence $(>25 \%)$ of accessory roots ${ }^{[2,3]}$.

The present case report represents the endodontic management of mandibular first premolar with two roots.

\section{Case Report}

A 28 years old female patient referred to department of conservative and endodontics with the chief complaint of pain in left lower back teeth region since 7 days. Patient had given a history of incomplete root canal treatment from a private clinic.

2.1 Clinical and radiographic Examination: Clinical examination revealed a dislodged temporary restoration from left mandibular first premolar (34) with incomplete access opening. Slight tenderness on percussion was present with no abnormality detected on labial and lingual mucosa. Radiographic examination revealed 34 with bifurcated root (mesial and distal root) at the level of middle third to apical third and also there was widening of the apical periodontium suggestive of periapical pathology (Fig 1A). Hence the clinical and radiographic examination led to a provisional diagnosis of symptomatic apical periodontitis with respect to left mandibular first premolar requiring completion of root canal therapy.

2.2 Treatment done: Root canal treatment was completed in two visits. In first visit tooth i.e 34 was anaesthetized by giving inferior alveolar nerve block using $2 \%$ lignocaine with 1:80000 adrenaline (Lignox). Subsequently, the tooth was isolated with a rubber dam (Hygenic-Coltene). Endodontic access that was done previously in a private clinic was refined and pulp chamber was inspected under dental operating microscope (Labomed Dental Microscope) and a sharp DG 16 explorer was used to locate both canal orifices (Fig 1B). 
Working length of both the canals were initially determined by electronic apex locator (ROOT ZX II, J Morita) and then verified by IOPA (Fig 1C). Biomechanical preparation was done with crown down technique using Protaper Gold rotary NiTi files (Dentsply) till size F3 under copious irrigation with $5.25 \%$ sodium hypochlorite and $17 \%$ EDTA sequentially. Then canals were dried with paper points followed by temporization of tooth with Cavit (3M ESPE). Second visit was scheduled after 3 days. Patient became asymptomatic on her second visit, hence root canal treatment was completed in second visit. Final irrigation was done with $5 \mathrm{ml}$ of $5.25 \%$ sodium hypochlorite solution for $1 \mathrm{~min}$, then $5 \mathrm{ml}$ of $17 \%$ EDTA solution followed by the final rinse with $2 \mathrm{ml}$ of saline to cease irrigants activity. Irrigant activation was performed by using the 25/04 polymer tip of the EndoActivator (Dentsply). Canals were dried with paper points and the master cone radiograph was taken (Fig 1D). The canals were then obturated with size F4 Dentsply Protaper universal gutta percha point and AH plus sealer (Dentsply) using Single cone technique. A post obturation radiograph was taken to evaluate the quality of obturation (Fig 1E). Finally tooth was temporized and patient recalled after 1 week for post endodontic restoration.

\section{Discussion}

The endodontic failure is usually due to the failure in recognizing the variations in root and its root canal anatomy. Hence, it is crucial to be well aware of the commonest possible aberrations or anamolies of the tooth being treated ${ }^{[2]}$. Hoen and Pink ${ }^{[4]}$ found that the most common reason behind the retreatment cases are missed canals and the incidence of these missed canals are $42 \%$, which emphasises the importance of locating all the canals during a nonsurgical endodontic therapy. Many factors contributes to these aberrations found in the number of root or the root canal space configuration of permanent teeth like age, gender and ethnic background of the population studied ${ }^{[5,6]}$. Slowey et $a l$. has indicated that these variations in mandibular premolars probably because of exhibits ethnic variation ${ }^{[1]}$.

Exact etiology of an accessory root formation is not known, but it is suggested that traumatic injuries during root formation might results in ingrowth of tissue from hertwig's epithelial root sheath, which leads to the formation of extra root and extra canals ${ }^{[7]}$.

The level of bifurcation is very significant because the case difficulty is determined directly by the location of this level. The more apically the furcation area is located, the more difficult is the case. In the present case IOPA revealed that the bifurcation of the root was present at the level of middle third, hence it was decided to complete the endodontic treatment under the dental operating microscope ${ }^{[8,9]}$.

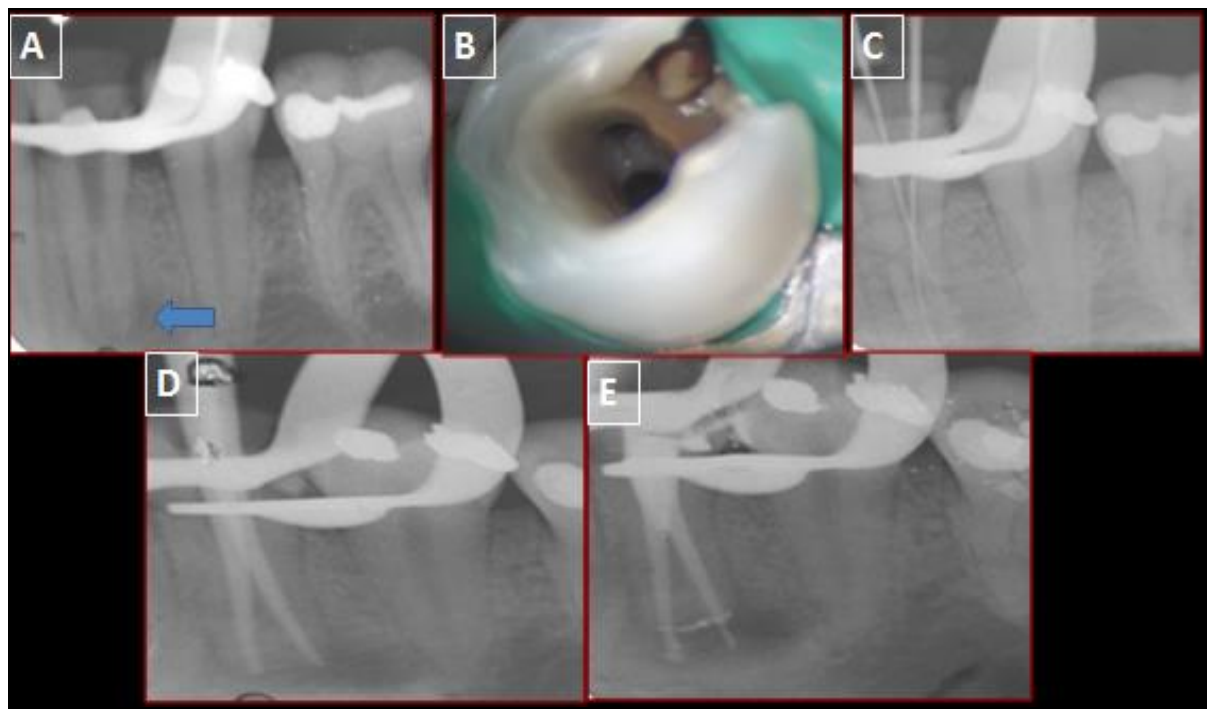

Fig 1: (A) Preoperative IOPA; (B) Clinical view under microscope; (C) Working length IOPA; (D) Master cone IOPA; (E) Postoperative IOPA

\section{Conclusion}

Lack of the knowledge of developmental variations might results in failure of endodontic treatment due to missed canal, however with the advances in modern endodontic techniques and the sound knowledge of complex root canal system can results in successful endodontic treatment.

\section{References}

1. Slowey RR. Root canal anatomy. Road map to successful endodontics. Dent clin North Am. 1979; 23:555-73.

2. Scott GR, Turner CG. Anthropology of modern human teeth. Cambridge: Cambridge University Press, 1997, 382-p.

3. Kararia N, Chaudhary A, Kararia V. Mandibular left first premolar with two roots: A morphological oddity. Contemporary clinical dentistry. 2012; 3(2):234.

4. Hoen MM, Pink FE. Contemporary endodontic retreatments: an analysis based on clinical treatment findings. Journal of endodontics. 2002; 28(12):834-6.
5. Sert S, Bayirli GS. Evaluation of the root canal configurations of the mandibular and maxillary permanent teeth by gender in the Turkish population. $\mathbf{J}$ Endod. 2004; 30:391-398.

6. Iyer VH, Indira R, Ramachandran S, Srinivasan MR. Anatomical variations of mandibular premolars in Chennai population. Indian J Dent Res. 2006; 17:7-10.

7. Prakash R, Nandini S, Ballal S, Kumar SN, Kandaswamy D. Two-rooted mandibular second premolars: Case report and survey. Indian Journal of Dental Research. 2008; 19(1):70.

8. Fossati C. Retreatment of a mandibular second premolar with two canals in two roots. Giornale italiano di endodonzia. 2018; 32(1):31-5.

9. Sonarkar S, Purba R, Badole G, Makade C. Unusual root canal morphology of mandibular second premolars: A case series and review. Journal of Dental Research and Review. 2017; 4(4):107. 